\title{
Withdrawing an explicit request for euthanasia or physician-assisted suicide: a retrospective study on the influence of mental health status and other patient characteristics
}

\author{
ISABELLE MARCOUX ${ }^{1,2 *}$, BREGJE D. ONWUTEAKA-PHILIPSEN ${ }^{1}$, \\ MARIJKE C. JANSEN-VAN DER WEIDE ${ }^{1}$ AND GERRIT VAN DER WAL ${ }^{1}$ \\ ${ }^{1}$ Vrije Universiteit Medical Center, Department of Public and Occupational Health and Institute for Research \\ in Extramural Medicine, Amsterdam, The Netherlands; ${ }^{2}$ Center for Research and Intervention on Suicide and \\ Euthanasia, Department of Psychology, University of Quebec at Montreal, Montreal, Canada
}

\begin{abstract}
Background. Mental health status may be closely related to an instability of intentions toward a premature death, but little is known about such instability following an explicit request for euthanasia or physician-assisted suicide (EAS) and patient characteristics associated with a change of mind.
\end{abstract}

Method. A questionnaire was sent to 6596 general practitioners in The Netherlands (response rate $60 \%$ ). Of these, 1681 provided descriptions of the most recent explicit request for EAS they had received in the preceding 18 months.

Results. Symptoms of depression and anxiety were related to a change of mind, but no relationship was found with the total score of the NOSGER Mood Dimension. Multinomial regression analysis revealed that patients who changed their mind had more mental health problems and less mental clarity than those who died by EAS. They also had fewer general health problems, had less unbearable and pointless suffering (according to the physician), were less concerned about loss of dignity and alternative treatment options were more frequently available. A further analysis revealed that mental health problems were more prevalent among patients whose requests were refused than among those who changed their mind. The physicians' evaluations of the reasons why a patient requested EAS were similar to a more objective measure of the patient characteristics.

Conclusions. These findings suggest that mental health status must be carefully assessed, and possible instability of desire must be taken into account in the course of a request for EAS. These results require replication, and future studies should adopt a prospective method.

\section{INTRODUCTION}

During the past few decades, societal debate on euthanasia and physician-assisted suicide (EAS) has resulted in a growing number of studies which have enhanced our knowledge of these topics. Despite legal prohibition of these

\footnotetext{
* Address for correspondence: Dr Isabelle Marcoux, CRISE, UQAM, C.P. 8888 succ. C., Montréal, Québec, Canada, H3C 3P8.

(Email:marcoux.isabelle@uqam.ca)
}

practices in most countries, research has revealed that a number of patients request their physician to perform EAS. For example, national surveys from the USA (Emanuel et al. 1996, 2000a; Carver et al. 1999; Meier et al. 1998) and Canada (Kinsella \& Verhoef, 1993) estimated that over $20 \%$ of physicians have received at least one request to assist a terminally ill patient to die by performing EAS. This percentage seems to be lower in Italy, 
where $11 \%$ of general practitioners reported a request for euthanasia (Grassi et al. 1999), while in the UK (Ward \& Tate, 1994) and Australia (Baume \& O'Malley, 1994; Stevens \& Hassan, 1994) such a request seems to be more frequent, with a prevalence of over $45 \%$. In The Netherlands, where these practices have been accepted under certain conditions for several years, it is estimated that physicians received 34700 requests for EAS in the later stages of disease in 2001, $9700(28 \%)$ of which were explicit requests (Onwuteaka-Philipsen et al. $2003 \mathrm{~b}$ ). Two-thirds of these requests were granted, and EAS was performed.

Several studies investigated the characteristics of patients who wish to die by EAS, and why they address such a request to their physician. In general, the results are based on two different types of methodology: (1) studies focusing on terminally ill patients, which compared the characteristics of those who had expressed a wish to die or had talked about EAS, with those who had not; and (2) studies in which physicians were asked about the reasons why patients requested EAS. According to physicians and nurses, a request for EAS is usually of a multifactorial nature, involving reasons such as not wanting to be dependent on others for personal care, putting a high value on autonomy, fear of pain, fear of being a burden for the family, loss of dignity, social isolation, etc. (Back et al. 1996; Verhoef \& van der Wal, 1997; Sullivan et al. 2001; Virik \& Glare, 2002; Marquet et al. 2003), but the most important concerns are usually non-physical (Back et al. 1996; Ganzini et al. 2000). This observation is corroborated by a trend analysis of requests for EAS during the period 1977-2001 in The Netherlands, which demonstrated that pain became significantly less important, whereas deterioration and loss of dignity became more relevant (Marquet et al. 2003). This change in trend could be partly explained by a change in cultural values, with more emphasis on autonomy, and also by the improvements that have been achieved in pain management.

Most studies focusing on terminally ill patients have investigated three different types of factors that could influence a desire for EAS. The factors in the first category are related to physical status (Breitbart et al. 2000; Wilson et al. 2000; Kelly et al. 2003), but the influence of pain in such a desire is not as clear. For example, Emanuel et al. (1996) observed that oncology patients experiencing pain at the moment of the interview were more likely to find EAS unacceptable. However, in some studies, the ratings of pain were related to a desire for death (Chochinov et al. 1995), but in others were not (Breitbart et al. 2000). In the second category, personal or social concerns were sometimes taken into account, and it was demonstrated that loss of control (Wilson et al. 2000) low family or social support (Chochinov et al. 1995; Breitbart et al. 2000; Kelly et al. 2003) and a greater perception of being a burden on others (Kelly et al. 2003) are important determinants of interest for EAS. In the third category, the most prevalent factors were found to be those associated with the mental status of the patient. The findings revealed a strong relationship between desiring, considering or having discussed EAS and depression (Chochinov et al. 1995; Emanuel et al. 1996; Kohlwes et al. 2001; Tiernan et al. 2002), hopelessness (Breitbart et al. 2000; Wilson et al. 2000) and anxiety (Kelly et al. 2003).

Another important finding is that attitudes and desires related to EAS are not necessarily stable over time, and that patients with depressive symptoms are more likely to change their mind (Blank et al. 2001; Emanuel et al. $2000 \mathrm{~b}$ ). In addition to depression, the presence of dyspnea symptoms (Emanuel et al. 2000a), greater suffering and lower instrumental support (Blank et al. 2001) were also related to a change of mind. This stresses the importance for the physician of adequately evaluating the patient's mental health status when a desire for EAS is expressed. Since EAS involves irreversible actions, it is important to have a better understanding of the instability of a wish to hasten death, in particular for those who go through the process of making an explicit request to their physician. One study in Oregon revealed that $15 \%$ of patients who requested assistance with suicide from their physician changed their mind after the 15-day waiting period (Ganzini et al. 2000). It is also known from a previous Dutch report that a small percentage of patients $(13 \%)$ changed their mind after making an explicit request for EAS (Onwuteaka-Philipsen et al. $2003 a$ ). Although the occurrence of such a situation is rare, this group of patients is clinically 
important. Therefore, the objective of the present study was to identify specific characteristics of patients who change their mind after making an explicit request for EAS, since this knowledge may be helpful for physicians during the decision-making process. The specific questions were: (1) Is mental health status related to a change of mind after making a request for EAS?

(2) What other characteristics are associated with the withdrawal of a request for EAS?

(3) Is there a difference between the physician's evaluation of the reasons why the patient made an explicit request for EAS and a more objective assessment of the patient's characteristics?

\section{METHOD}

\section{Definitions}

Euthanasia was defined as the administration of drugs with the explicit intention of ending the patient's life at his/her explicit request, and physician-assisted suicide as the prescription or supply of drugs with the explicit intention of enabling the patient to end his/her own life.

\section{Study design and participants}

The data presented in this article are derived from the evaluation study of the project 'Support and Consultation on Euthanasia in The Netherlands' (SCEN) (Onwuteaka-Philipsen et al. 2003a). The SCEN is a network of specifically trained physicians who can be contacted by general practitioners (GPs) for information, advice, and/or a formal consultation, as required in the euthanasia notification procedure. For the purpose of this study, all GPs in 18 (out of 23) regions of The Netherlands received a questionnaire approximately 18 months after SCEN was established in their region (in 2001 and 2002). The addresses of all these GPs were obtained from the GP registers. Of the 6596 GPs who received a questionnaire, 556 were no longer working in the selected region, or had retired or were ill. A total of 3615 GPs returned the questionnaire (response rate $60 \%$ ). Anonymity was guaranteed by a procedure involving an intermediary, so that no connection could be made between a physician and the content of a questionnaire by either the intermediary or the researchers.

The part of the questionnaire that is relevant for this article is that in which GPs were asked whether they had received an explicit request for EAS in the previous 18 months; if so, they were asked to describe their most recent case. A total of 1681 GPs had received such a request and provided the relevant information.

\section{Outcome variable}

Information about the dependent variable, a change of mind, was obtained by asking the physician the following question: 'Did you finally grant the request for euthanasia or physician-assisted suicide?' The physician could choose between the following response options: 'yes, euthanasia was performed'; 'yes, physician-assisted suicide was performed'; 'no, I refused the request'; 'no, the patient died before the final decision was made'; 'no, the patient died before EAS could be performed'; and 'no, the patient did not want it any more'. The variable was then categorized into three categories: those who changed their mind $(13 \%)$, those who did not change their mind $(44 \%)$ (i.e. those who died by euthanasia or physician-assisted suicide) and those for whom it was not known whether they would have changed their mind $(43 \%)$ ) (including patients whose request was refused, those who died before the final decision was made, and those who died before EAS could be performed).

\section{Independent variables}

Most of the information about the patient resulted from two different types of questions. First, a clinical evaluation of the patient at the end of the decision-making process, in terms of physical or psychological symptoms (pain, inactivity, tiredness, nausea, vomiting, cough, loss of appetite, dyspnea, anxiety, feeling depressed, confusion, consciousness, feeling bad) in which each item was rated on a five-point Likert scale, ranging from 'none' to 'a lot'. Secondly, reasons why the patient made the request for EAS according to the physician (pain, vomiting, fear of suffocation, invalidity, depression, not wanting to be a burden for the family, fear of loss of dignity, tiredness, tired of life, pointless suffering, other reason), where multiple choices were allowed. Even though both types of information were obtained from the physician, the latter type is explicitly related to the request, while the former is not. 
In addition to questions about psychological symptoms, the Mood Dimension of the NOSGER (Nurses' Observation Scale for Geriatric Patients) was also used to evaluate the mental status of the patient. Although it was originally developed for geriatric patients, this questionnaire was chosen because it was designed to be filled in by somebody other than the patient, unlike most other mental health evaluation instruments. The NOSGER Mood Dimension was designed as a clinical rating instrument that can be used by those in close contact with the patient. It consists of five items concerning behaviour (reports of feeling sad, reports of feeling worthless, appearing sad or tearful, appearing to be cheerful, enjoying certain events), each rated on a five-point scale for frequency of occurrence. Validation studies have demonstrated that the dimension has an inter-rater reliability of $0.60-0.79$ and a test-retest reliability of 0.75-0.85 (Spiegel et al. 1991).

Finally, apart from the gender and age of the patient, questions were also asked about the degree of explicitness of the request, the degree of unbearable and hopeless suffering (to a very high degree/to a high degree/to a lesser degree), the presence of alternative treatment options (yes/no) and the competence of the patient (no/ not fully/yes).

\section{Statistical analysis}

In order to determine which patient characteristics can explain a change of mind after making an explicit request for EAS, multinomial logistic regression analysis was applied. Missing data on symptom evaluation (between 52 and 95) and reasons affecting a request for EAS according to the physician (between 33 and 38), were replaced by the mean score of the item. The analyses were performed separately to determine whether there was a difference in the explanation of a change of mind between the two types of information: (1) the physician's evaluation of reasons affecting the request, and (2) factual patient characteristics according to symptom evaluation. Items related to the mental status of the patient were first entered in the analysis, because of their reported importance in previous studies.

Before the regression analysis was performed, an exploratory factor analysis was applied to reduce the large number of observed variables to a smaller number of factors and also to reveal correlation patterns among observed variables (Tabachnick \& Fiddell, 2000). The unweighted least squares (ULS) method of extraction was used because of its appropriateness for exploratory analysis and the fact that some variables are ordinal or do not meet the normality assumption. Eigenvalue, that is the total variance explained by each factor, of 1 or over, was retained and a Varimax rotation was applied. Factor loadings of more than 0.30 (minimal correlation between the variable and the factor) were retained in the analysis. The regression estimation method for factors was used, since it takes into account the correlation between the factor scores and is also the best method for construct validation. Although the sum-scores were not used, Cronbach's alpha coefficients were calculated to give an overview of the reliability of the variables included under each dimension.

\section{RESULTS}

\section{Mental health status of patients who changed their mind}

Table 1 presents the distribution of the variables used to measure the mental health status of patients who made an explicit request for EAS, and to compare those who changed their mind afterwards with those who did not (died by EAS). Analysis of variance showed no variation between groups in the total score of the NOSGER Mood Dimension $[F(1,1020)=$ $1 \cdot 930, p=0 \cdot 165$ ], but differences were found in two items. More specifically, patients who changed their mind more often appeared to be sad or tearful $[F(1,1046)=5 \cdot 601, p=0 \cdot 018]$ but also more often appeared to be cheerful $[F(1,1040)=4 \cdot 142, \quad p=0 \cdot 036]$. When withingroup differences were investigated, $25 \%$ of those who changed their mind appeared to be sad and tearful most of the time, but also cheerful $\left(\chi^{2}=9.698, p=0.001\right)$, compared with $17 \%$ of the patients who died by EAS $\left(\chi^{2}=99 \cdot 708, p<0 \cdot 0001\right)$

Secondly, in the evaluation of symptoms, two items were related to mental status and showed differences: patients who changed their mind were more likely to feel depressed $[F(1,1049)=$ $10 \cdot 951, p=0 \cdot 001]$ and be anxious $[F(1,1050)=$ 
Table 1. Mental health status of patients who changed their mind after making an explicit request for $E A S^{1}$ compared with those who died by EAS (percentages)

\begin{tabular}{|c|c|c|c|c|c|c|}
\hline & \multicolumn{3}{|c|}{ Changed their mind } & \multicolumn{3}{|c|}{ Did not change their mind (EAS) } \\
\hline & $n$ & $\begin{array}{c}\text { Never or } \\
\text { sometimes }\end{array}$ & $\begin{array}{l}\text { Often to } \\
\text { always }\end{array}$ & $n$ & $\begin{array}{c}\text { Never or } \\
\text { sometimes }\end{array}$ & $\begin{array}{l}\text { Often to } \\
\text { always }\end{array}$ \\
\hline \multicolumn{7}{|l|}{ Mood dimension (NOSGER) } \\
\hline Reports feeling sad (item 3 ) & 140 & $60 \cdot 7$ & $39 \cdot 3$ & 909 & $65 \cdot 5$ & $34 \cdot 5^{\mathrm{a}}$ \\
\hline Reports feeling worthless (item 10) & 139 & $71 \cdot 2$ & $28 \cdot 8$ & 907 & $75 \cdot 0$ & $25 \cdot 0^{\mathrm{b}}$ \\
\hline Appears sad or tearful (item 13) & 139 & $69 \cdot 1$ & $30 \cdot 9$ & 909 & $80 \cdot 0$ & $20 \cdot 0^{\mathrm{c}}$ \\
\hline Appears cheerful (item 25) & 140 & $49 \cdot 4$ & $50 \cdot 6$ & 902 & $60 \cdot 0$ & $40 \cdot 0^{\mathrm{d}}$ \\
\hline Enjoys certain events (item 28) & 138 & $49 \cdot 3$ & $50 \cdot 7$ & 900 & $53 \cdot 6$ & $46 \cdot 4^{\mathrm{e}}$ \\
\hline \multirow[t]{2}{*}{ Total score } & 137 & \multicolumn{2}{|c|}{ Mean (8.64); S.D.(3.821) } & 885 & \multicolumn{2}{|c|}{ Mean $(8 \cdot 17)$; s.D. $(3 \cdot 690)^{f}$} \\
\hline & $n$ & $\begin{array}{c}1 \text { or } 2 \\
\text { (low score) }\end{array}$ & $\begin{array}{c}3 \text { to } 5 \\
\text { (high score) }\end{array}$ & $n$ & $\begin{array}{c}1 \text { or } 2 \\
\text { (low score) }\end{array}$ & $\begin{array}{c}3 \text { to } 5 \\
\text { (high score) }\end{array}$ \\
\hline \multicolumn{7}{|l|}{ Symptom evaluation } \\
\hline Depression & 142 & $78 \cdot 2$ & $21 \cdot 8$ & 909 & $70 \cdot 4$ & $29 \cdot 6^{\mathrm{g}}$ \\
\hline Anxiety & 142 & $90 \cdot 5$ & $9 \cdot 5$ & 910 & $87 \cdot 0$ & $13 \cdot 0^{\mathrm{h}}$ \\
\hline
\end{tabular}

EAS, Euthanasia or physician-assisted suicide.

${ }^{\mathrm{a}} \chi^{2}=1 \cdot 196, p=0 \cdot 296 ;{ }^{\mathrm{b}} \chi^{2}=0.891, p=0 \cdot 348 ;{ }^{\mathrm{c}} \chi^{2}=8 \cdot 517, p=0 \cdot 005 ;{ }^{\mathrm{d}} \chi^{2}=5 \cdot 402, p=0.023 ;{ }^{\mathrm{e}} \chi^{2}=0 \cdot 880, p=0 \cdot 361 ;{ }^{\mathrm{f}} F(1,1020)=1 \cdot 930$, $p=0 \cdot 165 ;{ }^{\mathrm{g}} \chi^{2}=18 \cdot 996, p<0 \cdot 0001 ;{ }^{\mathrm{h}} \chi^{2}=26 \cdot 280, p<0 \cdot 0001$.

$22 \cdot 496, p<0 \cdot 001]$ than those who did not change their mind and died by EAS.

\section{Assessment of patient characteristics}

Factor analysis was performed in order to reduce the large number of observed variables to a smaller number of factors. Of the 39 observed variables, 17 were minimally correlated with one or several variables; they were then retained in the analysis and this resulted in a five-factor model, which explained $49 \cdot 5 \%$ of the variance. Only items related to the evaluation of symptoms were retained in the analysis, and the five factors were characterized as mental health problems (explaining $15 \%$ of the variance), general health problems (explaining 10\%), weak mental clarity (explaining $8 \%$ ), digestive symptoms (explaining $8 \%$ ) and respiratory symptoms (explaining $8 \%$ ). Table 2 shows the rotated component matrix of the factor analysis with the internal consistency of each factor, which was moderate to high (Cronbach's alpha from 0.72 to $0 \cdot 79$ ).

The outcome variable was also included in the initial analysis to reveal possible patterns of correlation with the independent variables. Three were strongly related to the fact that patients had changed their mind after making an explicit request for EAS, and were then removed from the final model. A change of mind was positively correlated with the presence of alternative treatment options (Pearson's $r=0 \cdot 39, p<0 \cdot 0001$ ), and negatively with both the degree of explicitness of the request (Pearson's $r=-0.49, p<0 \cdot 0001)$ and of hopeless suffering (Pearson's $r=-0.35, p<0 \cdot 0001$ ). More specifically, $91 \%$ of patients who did not change their mind (died by EAS) made the request with a very high degree of explicitness, while only $31 \%$ of those who changed their mind made it with the same intensity. The same pattern prevails for the extent to which the suffering was hopeless at the end of the decision-making process: patients who did not change their mind (died by EAS) experienced a very high degree of hopeless suffering (due to lack of additional available medical interventions) more frequently $(84 \%)$ than those who changed their mind $(52 \%)$. Finally, curative or palliative treatment was more often possible for patients who changed their mind $(57 \%)$ than for those who died by EAS $(10 \%)$.

\section{Patient characteristics related to a change of mind after making an explicit request for EAS}

Multinomial regression analysis was first performed separately, that is, with only symptom evaluation, on the one hand, and the 
Table 2. Factor analysis with determinants of patients who made an explicit request for EAS

\begin{tabular}{|c|c|c|c|c|c|c|}
\hline \multirow[b]{2}{*}{ Indicators } & \multirow[b]{2}{*}{ Communalities } & \multicolumn{5}{|c|}{ Factors } \\
\hline & & Factor $1^{\mathrm{a}}$ & Factor $2^{\mathrm{b}}$ & Factor $3^{\mathrm{c}}$ & Factor $4^{\mathrm{d}}$ & Factor $5^{\mathrm{e}}$ \\
\hline \multicolumn{7}{|l|}{ Mental health problems } \\
\hline NOSGER (item 13) & $0 \cdot 46$ & $0 \cdot 73^{*}$ & $0 \cdot 02$ & $0 \cdot 08$ & $0 \cdot 01$ & $0 \cdot 00$ \\
\hline NOSGER (item 3) & $0 \cdot 44$ & $0 \cdot 70^{*}$ & $-0 \cdot 01$ & $0 \cdot 02$ & $-0 \cdot 01$ & $-0 \cdot 03$ \\
\hline Depressive symptoms & $0 \cdot 42$ & $0.67 *$ & $-0 \cdot 05$ & $0 \cdot 12$ & $0 \cdot 11$ & $0 \cdot 11$ \\
\hline NOSGER (item 25) & $0 \cdot 41$ & $0.62 *$ & $0 \cdot 16$ & $0 \cdot 03$ & $-0 \cdot 01$ & $-0 \cdot 02$ \\
\hline Anxiety symptoms & $0 \cdot 35$ & $0 \cdot 49^{*}$ & -0.09 & $0 \cdot 18$ & $0 \cdot 13$ & $0 \cdot 26$ \\
\hline NOSGER (item 10) & $0 \cdot 24$ & $0 \cdot 47^{*}$ & $0 \cdot 10$ & $-0 \cdot 02$ & $-0 \cdot 12$ & $-0 \cdot 05$ \\
\hline NOSGER (item 28) & $0 \cdot 32$ & $0 \cdot 47^{*}$ & $0 \cdot 19$ & $0 \cdot 00$ & $-0 \cdot 04$ & $0 \cdot 00$ \\
\hline \multicolumn{7}{|l|}{ General health problems } \\
\hline Feeling bad & $0 \cdot 39$ & $0 \cdot 19$ & $0 \cdot 69^{*}$ & $-0 \cdot 01$ & $0 \cdot 14$ & 0.09 \\
\hline Tired & $0 \cdot 35$ & $0 \cdot 02$ & $0.64 *$ & $0 \cdot 04$ & $0 \cdot 10$ & $0 \cdot 15$ \\
\hline Loss of appetite & $0 \cdot 33$ & $0 \cdot 02$ & $0 \cdot 60^{*}$ & $0 \cdot 01$ & $0 \cdot 24$ & $0 \cdot 01$ \\
\hline Not active & $0 \cdot 20$ & $0 \cdot 06$ & $0 \cdot 52^{*}$ & $0 \cdot 03$ & $-0 \cdot 05$ & $0 \cdot 03$ \\
\hline \multicolumn{7}{|l|}{ Weak mental clarity } \\
\hline Confused & $0 \cdot 42$ & $0 \cdot 11$ & $0 \cdot 01$ & $0 \cdot 99 *$ & $0 \cdot 01$ & $0 \cdot 04$ \\
\hline Low consciousness & $0 \cdot 40$ & $0 \cdot 08$ & $0 \cdot 05$ & $0 \cdot 61^{*}$ & $-0 \cdot 01$ & $0 \cdot 00$ \\
\hline \multicolumn{7}{|l|}{ Digestive symptoms } \\
\hline Vomiting & $0 \cdot 45$ & $-0 \cdot 02$ & $0 \cdot 11$ & $-0 \cdot 01$ & $0 \cdot 84 *$ & $0 \cdot 02$ \\
\hline Nausea & $0 \cdot 47$ & $-0 \cdot 02$ & $0 \cdot 23$ & $0 \cdot 01$ & $0 \cdot 74 *$ & $0 \cdot 00$ \\
\hline \multicolumn{7}{|l|}{ Respiratory symptoms } \\
\hline Dyspnea & $0 \cdot 44$ & $0 \cdot 01$ & $0 \cdot 19$ & $0 \cdot 01$ & $-0 \cdot 05$ & $0 \cdot 81^{*}$ \\
\hline Cough & $0 \cdot 42$ & $0 \cdot 03$ & $0 \cdot 08$ & $0 \cdot 02$ & $0 \cdot 06$ & $0.75^{*}$ \\
\hline
\end{tabular}

NOSGER: Nurses' Observation Scale for Geriatric Patients.

${ }^{\mathrm{a}}$ Factor $1($ mean $=11 \cdot 017$, variance $=25 \cdot 51$, alpha $=0 \cdot 79) ;{ }^{\mathrm{b}}$ Factor $2($ mean $=12 \cdot 86$, variance $=8 \cdot 34$, alpha $=0 \cdot 72) ;{ }^{\mathrm{c}}$ Factor $3($ mean $=0 \cdot 97$, variance $=2 \cdot 69$, alpha $=0 \cdot 76) ;{ }^{\mathrm{d}}$ Factor $4($ mean $=3 \cdot 00$, variance $=5 \cdot 84$, alpha $=0 \cdot 79) ;{ }^{\mathrm{e}}$ Factor $5($ mean $=3 \cdot 59$, variance $=6 \cdot 20$, alpha $=0 \cdot 78)$.

* Factor loadings of more than $0 \cdot 3$ were retained.

reasons for an explicit request according to the physician, on the other hand. With the exception of items related to personal considerations (loss of dignity and fear of being a burden for the family), included in the reasons for an explicit request according to the physician, the items in the two different measures were quite similar. Since the results of the two multinomial regression analyses were comparable, it was decided to consider all the variables together (see Table 3). Gender and age were removed from the analysis, since they were not related to a change of mind after making an explicit request for EAS, and also because of numerous missing data $($ gender $=63$, age $=91$ ).

The model presented in Table 3 explains $27 \%$ of the variance, and reveals that patients who changed their mind after making an explicit request for EAS had a poorer mental health status than those who did not change their mind and died by EAS. Specifically, they were 1.5 times more likely to have mental health problems and to have weaker mental clarity than those who died by EAS. However, the latter patients had a worse physical health status: they were twice as likely to have general health problems and more likely to have unbearable suffering ( 8 times) and pointless suffering ( $1 \cdot 3$ times). Those who died by EAS were also more concerned about deterioration and loss of dignity ( $1 \cdot 2$ times). The only differences between the patients who changed their mind and those for whom it is not known whether they would have changed their mind, concerned physical health status and suffering: those who changed their mind had $1 \cdot 3$ times fewer physical health problems and three times less unbearable suffering.

An additional analysis was performed to compare the six original subgroups (euthanasia, physician-assisted suicide, change of mind, refused request, died before the final decision was made, died before EAS could be performed) with regard to possible disparities between the groups, mostly within the 'do not know' group (refused request, died before the final decision was made, died before EAS could be performed). Three differences were found: patients whose request was refused by the physician had 
Table 3. Odds ratios for patients' symptoms and reasons, according to the physician, associated with an explicit request for EAS by multinomial regression

\begin{tabular}{|c|c|c|c|c|}
\hline \multirow[b]{2}{*}{ Base group: patients who changed their mind } & \multicolumn{2}{|c|}{ Did not change their mind (EAS) } & \multicolumn{2}{|c|}{ Do not know ${ }^{\mathrm{a}}$} \\
\hline & OR & $95 \% \mathrm{CI}$ & OR & $95 \% \mathrm{CI}$ \\
\hline \multicolumn{5}{|l|}{ Mental health status } \\
\hline Mental health problems (S-F) & $0 \cdot 70^{* *}$ & $0 \cdot 56-0 \cdot 88$ & $1 \cdot 08$ & $0 \cdot 87-1 \cdot 34$ \\
\hline Weak mental clarity (S-F) & $0.67^{* * *}$ & $0 \cdot 57-0 \cdot 80$ & $0 \cdot 94$ & $0 \cdot 80-1 \cdot 10$ \\
\hline Depression (R) & 0.79 & $0 \cdot 57-1 \cdot 08$ & 0.92 & $0 \cdot 70-1 \cdot 20$ \\
\hline Tired of life (R) & $0 \cdot 96$ & $0 \cdot 78-1 \cdot 18$ & 0.99 & $0 \cdot 82-1 \cdot 20$ \\
\hline \multicolumn{5}{|l|}{ Physical health status } \\
\hline General health problems (S-F) & $1.98^{* * *}$ & $1 \cdot 59-2 \cdot 46$ & $1 \cdot 28 *$ & $1 \cdot 05-1 \cdot 57$ \\
\hline Respiratory symptoms (S-F) & 1.20 & $0.93-1 \cdot 54$ & $1 \cdot 10$ & $0 \cdot 86-1 \cdot 41$ \\
\hline Digestive symptoms (S-F) & $1 \cdot 12$ & $0 \cdot 86-1 \cdot 43$ & $0 \cdot 87$ & $0 \cdot 68-1 \cdot 12$ \\
\hline General weakness $(\mathrm{R})$ & $0 \cdot 98$ & $0 \cdot 85-1 \cdot 13$ & $0 \cdot 89$ & $0 \cdot 77-1 \cdot 02$ \\
\hline Invalidity/immobility (R) & $1 \cdot 28$ & $1 \cdot 00-1 \cdot 63$ & $1 \cdot 18$ & $0 \cdot 92-1 \cdot 50$ \\
\hline Suffocation (R) & $1 \cdot 11$ & $0 \cdot 90-1 \cdot 38$ & $1 \cdot 01$ & $0 \cdot 82-1 \cdot 25$ \\
\hline Vomiting (R) & $1 \cdot 23$ & $0 \cdot 88-1 \cdot 73$ & $1 \cdot 11$ & $0 \cdot 79-1 \cdot 57$ \\
\hline \multicolumn{5}{|l|}{ Pain and suffering } \\
\hline Pain (S) & $1 \cdot 19$ & $0 \cdot 99-1 \cdot 42$ & $1 \cdot 08$ & $0 \cdot 91-1 \cdot 28$ \\
\hline Unbearable suffering (S) & $8 \cdot 25^{* * *}$ & $4 \cdot 09-16 \cdot 65$ & $3 \cdot 08^{* *}$ & $1 \cdot 51-6 \cdot 27$ \\
\hline Pain (R) & $0 \cdot 84$ & $0 \cdot 70-1 \cdot 02$ & $0 \cdot 84$ & $0 \cdot 70-1 \cdot 01$ \\
\hline Pointless suffering (R) & $1 \cdot 30^{* * *}$ & $1 \cdot 13-1 \cdot 49$ & $1 \cdot 08$ & $0 \cdot 94-1 \cdot 23$ \\
\hline \multicolumn{5}{|l|}{ Personal considerations } \\
\hline Loss of dignity (R) & $1 \cdot 16^{*}$ & $1 \cdot 03-1 \cdot 31$ & $1 \cdot 05$ & $0 \cdot 93-1 \cdot 19$ \\
\hline Burden (R) & $0 \cdot 96$ & $0 \cdot 81-1 \cdot 13$ & $1 \cdot 01$ & $0 \cdot 86-1 \cdot 18$ \\
\hline
\end{tabular}

EAS, Euthanasia and physician-assisted suicide; OR, odds ratio; CI, confidence interval; S, symptoms (factual evaluation of the patient's condition); F, factor score (see Table 2); R, reasons (according to the physician, it was an important reason for the explicit request for EAS).

a Do not know: those for whom it is not known whether they would have changed their mind because: (1) the physician refused the request; (2) the patient died before the final decision was made; (3) the patient died before EAS could be performed; (4) of missing information.

* Significant at $p<0 \cdot 05, * *$ significant at $p<0 \cdot 01, * * *$ significant at $p<0 \cdot 001$.

more mental health problems [odds ratio (OR) $1 \cdot 5$, confidence interval (CI) 1.18-2.02] and fewer digestive symptoms (OR $0 \cdot 66$, CI $0 \cdot 46-$ $0.94)$ than those who changed their mind. And finally, those who died by EAS had more symptoms of pain (OR 1.3, CI 1.02-1.47) than those who changed their mind, whereas no difference was found when pain was considered to be an important reason for requesting EAS, according to the physician.

\section{DISCUSSION}

Some earlier studies have recognized that a wish to die is not always stable over time (Emanuel et al. $2000 a$; Blank et al. 2001). However, only a few of the patients who consider EAS as a future possibility, and even those who express such a wish or talk about this subject with relatives or their physician, will eventually make an explicit request. The study carried out by Ganzini et al. (2000) was the first to report that a small percentage of patients changed their mind after having requested a prescription for lethal medication in Oregon, but very little information was revealed about those patients. To our knowledge, this is the first paper with a specific focus on the characteristics of patients who changed their mind after going through the process of making an explicit request for EAS to their physician.

First, it was found that patients who changed their mind after making an explicit request for EAS seem quite similar to those who were unstable in their desire to hasten death at an earlier stage of the process (Emanuel et al. $2000 a$; Blank et al. 2001), since mental health problems were more prevalent. This finding emphasizes the physician's duty to detect potential depression or anxiety problems that could influence such a request. It is well known that psychological distress, and even major depression, are not rare among terminally ill patients (Breitbart \& Rosenfeld, 1999; Block, 2000; Lloyd-Williams et al. 2000), but these disorders tend to be under-recognized and 
under-treated (Passik et al. 1998; Meyer et al. 2003), and physicians themselves are sometimes concerned about the risk of undetected depression underlying a request for EAS (Curry et al. 2000). Explanations for such a problem are possible lack of knowledge and lack of skills to detect depression, but also the fact that it is difficult to differentiate between the 'normal' features of the dying process that some call lack of 'appropriate sadness' and depression, and the non-disclosure by the patients of their own mood (Lloyd-Williams, 2002). Nevertheless, the present study reveals that mental health status was worse in patients whose requests were refused than in those who changed their mind. This suggests that in The Netherlands, physicians are taking into account the possible influence of a patient's mental status in their decision-making. However, there is no available information about the subsequent treatment that is offered to those patients, and the effectiveness of such treatment ought to be addressed in future studies, since the results are still somewhat divergent. For example, Kugaya et al. (1999) showed that antidepressant treatment can be effective for terminally ill cancer patients to alleviate a wish to die due to major depression, while Ganzini et al. (2000) observed that only $11 \%$ of the patients changed their mind after requesting their physician to assist them to die, following a trial of medication for depression or anxiety or after being evaluated by a mental health expert. Furthermore, it must be taken into account that offering psychological treatment to a terminally ill person might sometimes be practically impossible owing to the patient's short life-expectancy.

Still considering mental health status, an interesting result emerged: patients who changed their mind were more likely to appear sad or tearful, but at the same time were also more likely to appear cheerful than those who did not change their mind and died by EAS. The fact that they seemed to be more ambivalent in their feelings, with quite unstable mood, strengthens the notion of instability among such patients. Their judgement may also be distorted since it was observed that they had more problems related to consciousness and confusion; this may be the case for patients suffering from delirium, which is a common complication at the end of life. Such findings imply that physicians must carefully investigate the equivocal nature of such a request, and whether the request is voluntary and well-considered. A parallel could be drawn between instability following an explicit request for EAS and the well-known ambivalence of suicidal individuals. Even if De Leo \& Spathonis (2003) suggested that suicide in late life is different from suicide in the other age groups, since there is more determination, more impulsivity and less ambivalence, this does not exclude the possibility that some terminally ill patients may be subject to hopelessness and despair that can be reduced by appropriate treatment.

It was also found that patients who changed their mind were less likely to have made a strong explicit request, that their suffering was not as hopeless as those who died by EAS, and that alternative treatment options were more frequently available. Unfortunately, we do not know the real reasons why patients changed their mind, but it is highly conceivable to assume that possible treatment alternatives proposed by the physician can affect such a desire or request. In fact, in a previous study it was found that patients who received a substantive intervention (control of pain or other symptoms; referral to a hospice programme; a mental health, social work, chaplaincy, or palliative care consultation; a trial of antidepressant medication) were more likely to change their mind (Ganzini et al. 2000). Such an opportunity must be carefully considered, since the requirements for prudent practice in The Netherlands state that the patient must be convinced that there is no other acceptable solution for his or her situation.

Another observation is that patients who changed their mind were probably at a less advanced stage of the dying process, since they had fewer general health problems and their sufferings were not considered to be as pointless and unbearable as those of the patients who died by EAS, according to the physician. The results of the present study are then quite similar to the results of other studies that compared granted and refused requests for EAS (Haverkate et al. 2000; Meier et al. 2003). Just like patients whose requests for EAS were refused, those who changed their mind after making an explicit request for EAS seemed less likely to be in a terminal phase and they tended to have more mental problems. 
The most important limitations of this study are related to the retrospective nature of the methodology. First, it can be assumed that physicians were probably more likely to report a case of EAS that had been performed than an incomplete case. Patients who changed their mind represented only $13 \%$ of all explicit requests, so information about these patients is therefore limited and sample bias may have occurred. Second, there is also potential inherent biases in retrospective reports by the physicians in reporting cases in concordance with the requirements for prudent practice and the procedures concerning EAS in The Netherlands. Furthermore, despite the fact that patient characteristics associated with an explicit request for EAS were analysed on the basis of two types of information (symptoms evaluation, and reasons for the request according to the physician), all the information came from the same source: the physician. Nevertheless, the fact that similar results were obtained from the two types of information suggests that physicians, as an external source, can be quite accurate in the assessment of what could influence a request for EAS. And finally, the questionnaire used to screen the mental status of the patients (the NOSGER Mood Dimension) has not been validated for terminally ill patients and was originally designed to be completed by someone in close, daily contact with the patient. It was not possible to know whether the physician was in such close contact with the patient. Those differences could explain the absence of significant results with regard to the total score obtained with this instrument.

In conclusion, even after an explicit request for EAS, some patients can show instability in their desire to hasten death with the assistance of their physician and can change their mind after making a request for EAS. Since those patients appear to be less ill and to be mentally less stable than those who die by EAS, this emphasizes the physician's duty to carefully and continuously assess the possible influence of psychological problems in such a request, to provide adequate mental care, and also to offer treatment alternatives when available. Because of the retrospective nature of this research, results must be carefully interpreted and eventually replicated. Future studies should adopt a prospective method, with appropriate, validated assessment tools. Such studies may help us better understand the instability of a desire for EAS after an explicit request has been made and how physicians should react in such a situation.

\section{ACKNOWLEDGEMENTS}

The data presented in this paper are drawn from the evaluation study of the project 'Support and Consultation on Euthanasia in The Netherlands' (SCEN), funded by grants from the Dutch Ministry of Health, Welfare and Sports. I.M. was the recipient of a grant from the Fonds québécois pour la recherche sur la société et la culture at the time of data analysis and manuscript preparation.

\section{DECLARATION OF INTEREST}

None.

\section{REFERENCES}

Back, A. L., Wallace, J. I., Starcks, H. E. \& Pearlman, R. A. (1996). Physician-assisted suicide and euthanasia in Washington State: patient requests and physician responses. Journal of the American Medical Association 275, 919-925.

Baume, P. \& O'Malley, E. (1994). Euthanasia: attitudes and practices of medical practitioners. Medical Journal of Australia 161, 137, 140, 142-144.

Blank, K., Robison, J., Prigerson, H. \& Schwartz, H. I. (2001) Instability of attitudes about euthanasia and physician assisted suicide in depressed older hospitalized patients. General Hospital Psychiatry 23, 326-332.

Block, S. D. (2000). Assessing and managing depression in the terminally ill patient. Annals of Internal Medicine 132, 209-218.

Breitbart, W. \& Rosenfeld, B. (1999). Physician-assisted suicide: the influence of psychosocial issues. Cancer Control 6, 146-161.

Breitbart, W., Rosenfeld, B., Pessin, H., Kaim, M., Funesti-Esch, J., Galietta, M., Nelson, C. J. \& Brescia, R. (2000). Depression, hopelessness, and desire for hastened death in terminally ill patients with cancer. Journal of the American Medical Association 284, 2907-2911.

Carver, A. C., Vickrey, B. G., Bernat, J. L., Keran, C., Ringle, S. P. \& Foley, K. M. (1999). End-of-life care: a survey of US neurologists' attitudes, behavior, and knowledge. Neurology $\mathbf{5 3}$, 284-293.

Chochinov, H. M., Wilson, K. G., Enns, M., Mowchun, N., Lander, S., Levitt, M. \& Clinch, J. J. (1995). Desire for death in the terminally ill. American Journal of Psychiatry 152, 1185-1191.

Curry, L., Gruman, C., Blank, K. \& Schwartz, H. I. (2000). Physicianassisted suicide in Connecticut: physicians' attitudes and experiences. Connecticut Medicine 64, 403-412.

De Leo, D. \& Spathonis, K. (2003). Suicide and euthanasia in late life. Aging Clinical and Experimental Research 15, 99-110.

Emanuel, E. J., Fairclough, D., Clarridge, B. C., Blum, D., Bruera, E., Penley, C., Schnipper, L. E. \& Mayer, R. J. (2000a). Attitudes and practices of U.S. oncologists regarding euthanasia and physicianassisted suicide. Annals of Internal Medicine 133, 527-532.

Emanuel, E. J., Fairclough, D., Daniels, E. R. \& Clarridge, B. R. (1996). Euthanasia and physician-assisted suicide: attitudes and 
experiences of oncology patients, oncologists, and the public. Lancet 347, 1805-1810.

Emanuel, E. J., Fairclough, D. L. \& Emanuel, L. L. (2000 b) Attitudes and desires related to euthanasia and physician-assisted suicide among terminally ill patients and their caregivers. Journal of the American Medical Association 284, 2460-2468.

Ganzini, L., Nelson, H. D., Schmidt, T. A., Kraemer, D. F., Delorit, M. A. \& Lee, M. A. (2000). Physicians' experiences with the Oregon Death with Dignity Act. The New England Journal of Medicine 342, 557-563.

Grassi, L., Magnani, K. \& Ercolani, M. (1999). Attitudes toward euthanasia and physician-assisted suicide among Italian primary care physicians. Journal of Pain and Symptom Management 17, 188-196.

Haverkate, I., Onwuteaka-Philipsen, B. D., van der Heide, A., Kostense, P., van der Wal, G. \& van der Maas, P. J. (2000). Refused and granted requests for euthanasia and assisted suicide in The Netherlands: interview study with structured questionnaire. British Medical Journal 321, 865-866.

Kelly, B., Burnett, P., Pelusi, D., Badger, S., Varghese, F. \& Robertson, M. (2003). Factors associated with the wish to hasten death: a study of patient with terminal illness. Psychological Medicine 33, 75-81.

Kinsella, T. D. \& Verhoef, M. J. (1993). Alberta euthanasia survey: 1. Physicians' opinions about the morality and legalization of active euthanasia. Canadian Medical Association Journal 148, 19211926.

Kohlwes, R. J., Koepsell, T. D., Rhodes, L. A. \& Pearlman, R. A. (2001). Physicians' responses to patients' requests for physicianassisted suicide. Archives of Internal Medicine 161, 657-663.

Kugaya, A., Akechi, T., Nakano, T., Okamura, H., Shima, Y. \& Uchitomi, Y. (1999). Successful antidepressant treatment for five terminally ill cancer patients with major depression, suicidal ideation and a desire for death. Support Care Cancer 7, 432-436.

Lloyd-Williams, M. (2002). Is it appropriate to screen palliative care patients for depression? American Journal of Hospice Palliative Care 19, 112-114.

Lloyd-Williams, M., Friedman, T. \& Rudd, N. (2000). Criterion validation of the Edinburgh postnatal depression scale as a screening tool for depression in patients with advanced metastatic cancer. Journal of Pain and Symptom Management 20, 259-275.

Marquet, R. L., Bartelds, A., Visser, G. J., Spreeuwenberg, P. \& Peters, L. (2003). Twenty-five years of requests for euthanasia and physician-assisted suicide in Dutch general pratice: trend analysis. British Medical Journal 327, 201-202.

Meier, D. E., Emmons, C.-A., Litke, A., Wallenstein, S. \& Morrison, S. (2003). Characteristics of patients requesting and receiving physician-assisted suicide. Archives of Internal Medicine 163, 1537-1542.

Meier, D. E., Emmons, C.-A., Wallenstein, S., Quill, T., Morrison, S. \& Cassell, C. K. (1998). A national survey of physician-assisted suicide and euthanasia in the United States. The New England Journal of Medicine 338, 1193-1201.

Meyer, H. A., Sinnott, C. \& Seed, P. T. (2003). Depressive symptoms in advanced cancer. Part 2. Depression over time; the role of the palliative care professional. Palliative Medicine 17, 604-607.

Onwuteaka-Philipsen, B. D., Jansen-van der Weide, M. C., Pasman, H. R. W. \& van der Wal, G. $(2003 a)$. Support and Consultation on Euthanasia in The Netherlands. Evaluation of Implementation and Effects. VUMC: Amsterdam.

Onwuteaka-Philipsen, B. D., van der Heide, A., Koper, D., Keij-Deerenberg, I., Rietjens, J. A., Rurup, M. L., Vrakking, A. M., Georges, J. J., Muller, M. T., van der Wal, G. \& van der Maas, P. J. (2003b). Euthanasia and other end-of-life decisions in The Netherlands in 1990, 1995, and 2001. Lancet $\mathbf{3 6 2}$, 395-399.

Passik, S. D., Dugan, W., McDonald, M. V., Rosenfeld, B., Theobald, D. E. \& Edgerton, S. (1998). Oncologists' recognition of depression in their patients with cancer. Journal of Clinical Oncology 16, 1594-1600.

Spiegel, R., Brunner, C., Ermini-Fünfschilling, D., Monsch, A., Notter, M., Puxty, J. \& Tremmel, L. (1991). A new behavioural assessment scale for geriatric out- and in-patients: the NOSGER (Nurses' Observation Scale for Geriatric Patients). Journal of the American Geriatric Society 39, 339-347.

Stevens, C. A. \& Hassan, R. (1994). Management of death, dying and euthanasia: attitudes and practices of medical practitioners in South Australia. Journal of Medical Ethics 20, 41-46.

Sullivan, A. D., Hedberg, K. \& Hopkins, D. (2001). Legalized physician-assisted suicide in Oregon, 1998-2000. New England Journal of Medicine 344, 605-607.

Tabachnick, B. G. \& Fiddell, L. S. (2000). Using Multivariate Statistics (4th edn). Pearson Allyn \& Bacon: Boston.

Tiernan, E., Casey, P., O'Boyle, C., Birkbeck, G., Mangan, M., O'Siorain, L. \& Kearney, M. (2002). Relations between desire for early death, depressive symptoms and antidepressant prescribing in the terminally ill patients with cancer. Journal of the Royal Society of Medicine 95, 386-390.

Verhoef, M. J. \& van der Wal, G. (1997). Euthanasia in family practice in The Netherlands. Toward a better understanding. Canadian Family Physician 43, 231-237.

Virik, K. \& Glare, P. (2002). Requests for euthanasia made to a tertiary referral teaching hospital in Sydney, Australia in the year 2000. Support Care Cancer 10, 309-313.

Ward, B. J. \& Tate, P. A. (1994). Attitudes among NHS doctors to requests for euthanasia. British Medical Journal 308, 1332-1334.

Wilson, K. G., Scott, J. F., Graham, I. D., Kozack, J. F., Chater, F., Viola, R. A., de Faye, B. J., Weaver, L. A. \& Curran, D. (2000). Attitudes of terminally ill patients toward euthanasia and physician-assisted suicide. Archives of Internal Medicine 160, 2454-2460. 